\title{
Classifying functional and non-functional model neurons using the theory of rough sets
}

\author{
Tomasz G Smolinski, , Astrid A Prinz \\ From Nineteenth Annual Computational Neuroscience Meeting: CNS*2010 \\ San Antonio, TX, USA. 24-30 July 2010
}

We explored a 12-dimensional parameter space of a 2-compartment model of the AB (anterior burster) neuron, which is one of the two cells that form the pacemaker kernel in the pyloric network in the lobster stomatogastric ganglion (STG). The computational exploration started with a hand-tuned $A B$ model [1] and systematically varied maximal conductances of membrane currents to determine ranges and variation steps that could potentially produce physiologically realistic behavior. We varied the conductances for the following currents in the model: fast sodium $I_{N a}$ and delayed-rectifier potassium $I_{K d}$ in the axon compartment, and delayed-rectifier $I_{K d}$, calcium-dependent $I_{K C a}$, transient potassium $I_{A}$, transient $I_{\mathrm{CaT}}$ and persistent $I_{\mathrm{CaS}}$ calcium, persistent sodium $I_{\mathrm{NaP}}$, and hyperpolarization-activated inward $I_{h}$ in the some/ neurite $(\mathrm{S} / \mathrm{N})$ compartment. To model the descending modulatory inputs, a voltage-gated inward current (such as the one activated by the neuropeptide proctolin) $I_{\text {proc }}$ was added to the $\mathrm{S} / \mathrm{N}$ compartment. Both compartments also contained the leak current $I_{L}$.

Every parameter set representing an individual model neuron was simulated and analyzed in terms of its period, burst duration, spike and slow wave amplitude, number of spikes per burst, spike frequency, and afterhyperpolarization potential, as well as the model's responses to neuromodulator deprivation and current injections. All of the above characteristics had to be within limits determined in physiological experiments performed on the $\mathrm{AB}$ cell, in order for a model to be classified as functional [2].

In addition to several other data mining and visualization techniques we have previously employed to analyze the parameter space of the "good" models [3], we propose to utilize the theory of rough sets (RS) to investigate the role and importance of the parameters in differentiating

\footnotetext{
* Correspondence: tomasz.smolinski@emory.edu

Department of Biology, Emory University, Atlanta, GA 30322, USA
}

between the functional and non-functional models. One of the most useful aspects of the RS theory in these kinds of classification tasks is the concept of a reduct-the smallest possible subset of attributes (i.e., maximal conductances in our model) that preserves the classification accuracy of the full set of attributes [4]. There are usually several such reducts for a given problem, and by extracting the so-called core of the reducts (i.e., the attributes that all the discovered reducts have in common), one can estimate the relative importance of the attributes. For instance, based on the 10 reducts computed from our dataset, we can state that soma $\mathrm{CaT}, \mathrm{NaP}, \mathrm{Kd}, \mathrm{KCa}$, and Proc, are absolutely necessary for differentiation between the functional and non-functional models (they were included in all 10 reducts), the axon $\mathrm{Na}$ current is very important (utilized in 9 out of 10 reducts), while the leak currents (both in the soma and the axon) seem to be the least important (they were present in 6 and 7 of the reducts, respectively). Furthermore, based on reducts, one can easily generate IF-THEN rules that not only describe how the model's proper behavior depends on its parameters, but also how those parameters (i.e., ionic currents) "cooperate" with one another to assure such activity. For example, one of the most trustworthy rules we discovered (confidence of 78\%) describes the following relationship:

IF soma $N a P \in[2.7 \mu \mathrm{S} \div 6.4 \mu \mathrm{S}) \quad A N D$ soma $K C a \in$ $[3,000 \mu \mathrm{S} \div 6,000 \mu \mathrm{S})$ AND axon $N a \in[300 \mu \mathrm{S} \div 450 \mu \mathrm{S})$

THEN "functional AB model,"

where the values in parentheses represent the ranges for the corresponding maximum membrane conductances.

\section{Acknowledgements}

Support contributed by: Burroughs-Wellcome Fund CASI Award to AAP.

Published: 20 July 2010 


\section{References}

1. Soto-Treviño, et al: Computational model of electrically coupled, intrinsically distinct pacemaker neurons. J Neurophysiol 2005, 94:590-604.

2. Smolinski, et al: Systematic selection of model parameter values matching biological behavior under different simulation scenarios. BMC Neuroscience 2008, 9(Suppl 1):53.

3. Smolinski, Prinz : Computational Intelligence in Modeling of Biological Neurons: A Case Study of an Invertebrate Pacemaker Neuron. Proc International Joint Conference on Neural Networks Atlanta, GA 2009.

4. Pawlak: Rough sets. Int I Computer and Information Sci 1982, 11:341-356.

doi:10.1186/1471-2202-11-S1-P157

Cite this article as: Smolinski and Prinz: Classifying functional and nonfunctional model neurons using the theory of rough sets. $B M C$

Neuroscience 2010 11(Suppl 1):P157.

Submit your next manuscript to BioMed Central and take full advantage of:

- Convenient online submission

- Thorough peer review

- No space constraints or color figure charges

- Immediate publication on acceptance

- Inclusion in PubMed, CAS, Scopus and Google Scholar

- Research which is freely available for redistribution

Submit your manuscript at www.biomedcentral.com/submit 